\title{
Nasopharyngeal carcinoma in a child with Kartagener's syndrome
}

\author{
Buket Kara ${ }^{1 \oplus}$, Nusret Seher ${ }^{2 \oplus}$, Meryem İlkay Eren Karanis ${ }^{3 \oplus}$, Mustafa Koplay $^{2 \oplus}$, \\ Hasibe Artaç ${ }^{4}$, Mehmet Koç ${ }^{5 \oplus}$, Ahmet Okay Çağlayann ${ }^{6,7}$, Yavuz Köksal ${ }^{1 \oplus}$
}

Departments of ${ }^{1}$ Pediatric Hematology and Oncology, ${ }^{2}$ Radiology and ${ }^{4}$ Pediatric Immunology and Allergy, Selcuk University Faculty of Medicine; ${ }^{3}$ Department of Pathology, Konya Education and Research Hospital; ${ }^{5}$ Department of Radiation Oncology, Necmettin Erbakan University Meram Faculty of Medicine, Konya, Turkey; ${ }^{6}$ Departments of Neurosurgery, Neurobiology, and Genetics, Yale University School of Medicine, New Haven, CT, USA, and 'Department of Medical Genetics, Dokuz Eylul University Faculty of Medicine, Izmir, Turkey.

\begin{abstract}
Background. Kartagener's syndrome, a subgroup of primary ciliary dyskinesia, is characterized by situs inversus totalis, chronic sinusitis and bronchiectasis. To date, the association of malignant diseases and Kartagener's syndrome has been reported and all cases except angioimmunoblastic $\mathrm{T}$ cell lymphoma in a child have been seen in adulthood.

Case. A 10-year-old boy who was followed with the diagnosis of Katagener's syndrome, presented with a progressive mass in the cervical region for 6 months. Physical examination revealed mental retardation, multiple lymphadenopathies, the largest in the left cervical region $(4 \times 4 \mathrm{~cm})$, and pectus carinatum. Also, on cardiovascular examination, apex beat was felt on the right fifth intercostal space along midclavicular line. Magnetic resonance imaging of nasopharynx showed narrowing of the nasopharyngeal airway with an increase in wall thickness up to $2.5 \mathrm{~cm}$ on the posterior wall of the nasopharynx. Also, bilateral multiple cervical lymphadenopathies were noted. The pathological examination of the biopsy from cervical lymphadenopathy revealed a diagnosis of undifferentiated nasopharyngeal carcinoma. Chemotherapy was started for nasopharyngeal carcinoma chemotherapy regimen including cisplatin, docetaxel, and 5-fluorouracil. After four cycles of chemotherapy there was a significant regression in nasopharyngeal mass and lymphadenopathies. The patient underwent radiotherapy to the nasopharynx and bilaterally cervical regions. The patient has been in follow-up for 6 years well and tumor free. However, he is still under the supervision of the pediatric immunology and allergy departments due to recurrent respiratory infections and sinusitis.
\end{abstract}

Conclusion. We present a case of nasopharyngeal carcinoma which developed in a child with Kartagener's syndrome. To our knowledge, this is the first report of nasopharyngeal carcinoma in a child with Kartagener's Syndrome.

Key words: Kartagener's syndrome, nasopharyngeal carcinoma, children.

Kartagener's syndrome (KS), is a rare and autosomal recessive primary ciliary dyskinesia. In KS the motility of the cilia is affected which leads to impaired mucociliary clearance. As a result, it causes recurrent chronic infections of the respiratory system. Generally, symptoms

$\bowtie \quad$ Yavuz Köksal

yavuzkoksal@yahoo.com

Received 16th April 2020, revised 29th June 2020, accepted 12th July 2020. begin shortly after birth. Kartagener's syndrome is characterized by a clinical triad including situs inversus, chronic sinusitis and bronchiectasis. ${ }^{1-3}$ Non-respiratory symptoms or signs such as chronic otitis media, conductive hearing loss, infertility in women and men, hydrocephalus and retinitis pigmentosa can be observed. ${ }^{2}$

In KS, a few malignancies have also been reported. These are renal cell carcinoma ${ }^{4-7}$, testicular germ cell tumor ${ }^{8,9}$, lung cancer ${ }^{10,11}$, carcinoma of the ethmoid labyrinth ${ }^{12}$, colon 
carcinoma $^{13}$, angioimmunoblastic $\mathrm{T}$ cell lymphoma ${ }^{14}$, adenosquamous carcinoma of the paranasal sinuses ${ }^{15}$, adenocarcinoma of the cervix uteri and endometrium ${ }^{16}$, adrenal adenocarcinoma ${ }^{17}$, and papillary thyroid carcinoma. ${ }^{18}$ Only one of these publications is a pediatric patient with the association of Kartagener syndrome and malignant disease. ${ }^{14}$

Herein, we present a case of nasopharyngeal carcinoma in a child with KS. To our knowledge, this is the first report of nasopharyngeal carcinoma in a child with KS.

\section{Case Report}

A 10-year-old boy presented with progressive mass in the cervical region for 6 months. With these complaints, antibiotic treatment was applied to the patient in another center and because his complaints were not resolved, subsequently, he was referred to our hospital. From his past medical reports we learned that he was treated in the neonatal intensive care unit for respiratory distress and birth asphyxia in neonatal period and he was operated for Morgagni hernia at 1 month of age. Situs inversus totalis was diagnosed during this period. Later, he was treated at the local center many times due to nasal congestion and frequent recurrent respiratory infections. He was the second child of consanguineous parents. His cousin who had situs inversus totalis also had recurrent respiratory infections. The investigations for recurrent respiratory infections including the immunoglobulin levels, alpha-1-antitripsin level and sweat chloride test were normal. The saccharin test is the only screening test that is unreliable in children aged $<12$ years but could not be done because of his mental retardation. In this patient, the diagnosis of KS was made based on clinical history of chronic upper and lower airway diseases, the presence of situs inversus totalis and positive family history (Fig. $1)$.

The genetic analysis is complicated by multiple existing phenotypes. Although genetic testing for some cases of PCD is possible, the Task Force Committee does not recommend it as part of initial diagnostic testing.

On admission, physical examination revealed mental retardation, multiple lymphadenopathies, the largest in the left cervical region $(4 \times 4 \mathrm{~cm})$, and pectus carinatum. Also, on cardiovascular examination, apex beat was felt on the right fifth intercostal space along midclavicular line. The remaining system examinations of the patient were unremarkable.

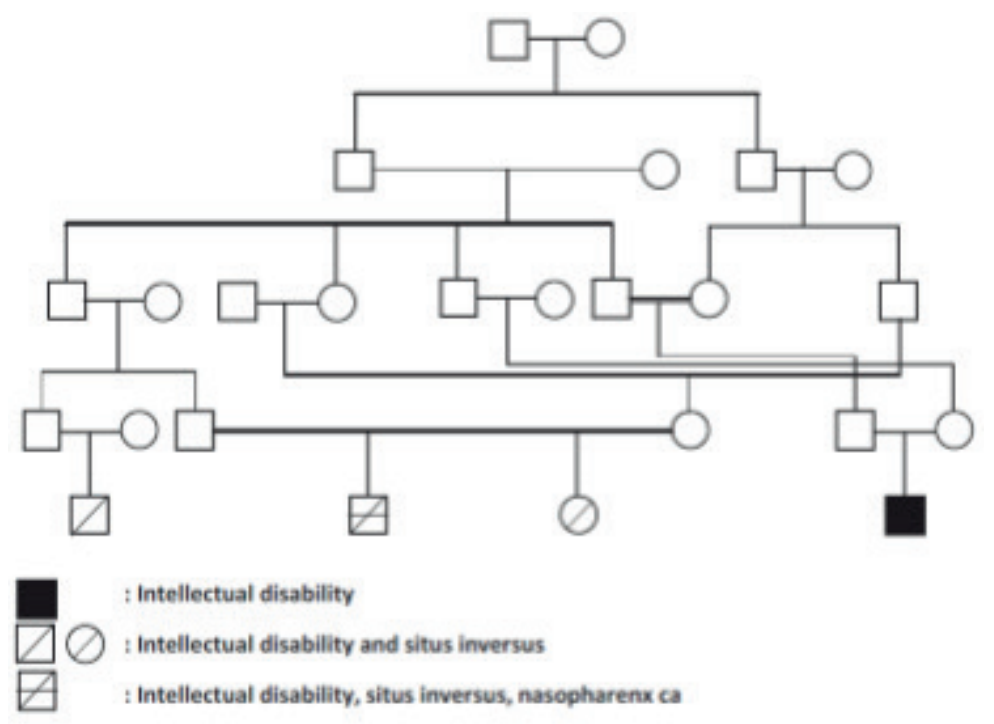

Fig. 1. The pedigree of the patient. 

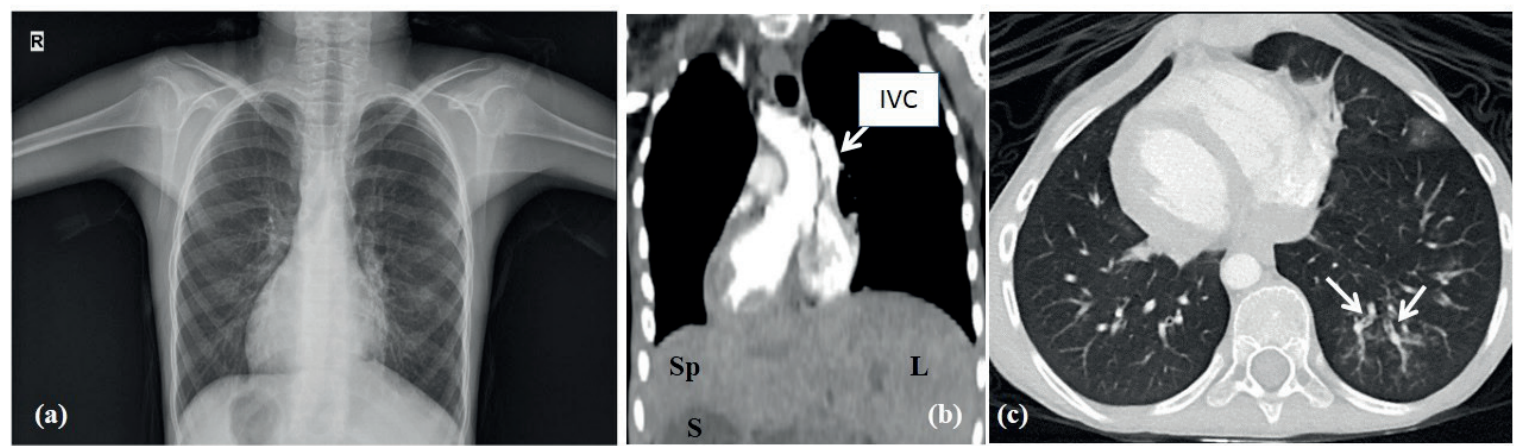

Fig. 2. (a) Posteroanterior chest $X$-ray showing dextrocardia; (b) Radiological findings of situs inversus totalis, IVC: inferior vena cava, Sp: spleen, S: stomach, and L: liver; (c) Minimal dilatation and thickening of bronchi in the left lung are shown.

Complete blood count, peripheral blood smear and biochemical examinations were normal. The posteroanterior chest X-ray showed dextrocardia (Fig. 2). Magnetic resonance imaging of nasopharynx showed narrowing of the nasopharyngeal airway with an increase in wall thickness up to $2.5 \mathrm{~cm}$ on the posterior wall of the nasopharynx (Fig. 3). Also, bilateral multiple cervical lymphadenopathies were seen.

The pathological examination of the biopsy from cervical lymphadenopathy revealed a diagnosis of undifferentiated nasopharyngeal carcinoma (Fig. 4). The patient was staged as III (T2N2M0) according to American Joint Committee on Cancer NPC staging classification, after a metastatic work-up had been completed. EBV serology was consistent with previous EBV infection. Nasopharyngeal carcinoma chemotherapy regimen including cisplatin $\left(75 \mathrm{mg} / \mathrm{m}^{2}\right.$, on day 1$)$, docetaxel (75 $\mathrm{mg} / \mathrm{m}^{2}$, on day 1) and 5-fluorouracil $(750 \mathrm{mg} /$ $\mathrm{m}^{2} /$ day, on days 1 to 4 ) was started. After four cycles of chemotherapy, there was significant regression in nasopharyngeal mass and lymphadenopathies. The radiotherapy of 60 Gy was given to nasopharynx and 54 Gy was delivered to the neck by intensity modulated radiation therapy with a simultaneous integrated boost. The patient has been in follow-up for 6 years without any recurrence. However, he is still under the supervision of the pediatric immunology and allergy department due to recurrent respiratory infections and sinusitis.

Written consent for publication of this case report and accompanying images was obtained from the parents of the patient.
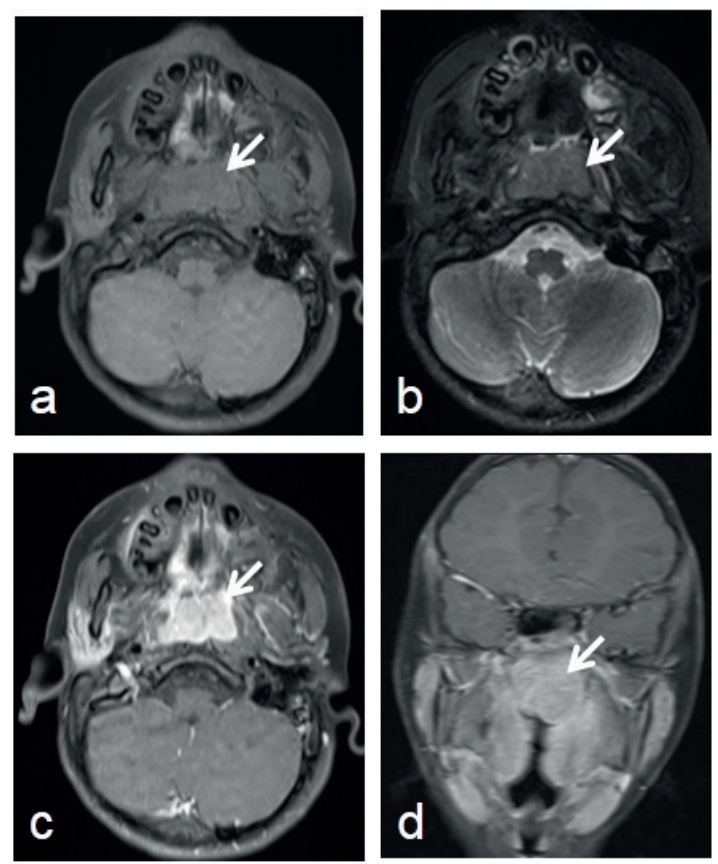

Fig. 3. Axial fat-saturated T1 (a) axial T2 (b) weighted images show a solid mass lesion (arrow) in the nasopharynx. Axial (c) and coronal (d) fat-saturated contrast enhancement T1-weigted images show marked contrast enhancement in the mass lesion (arrow). 

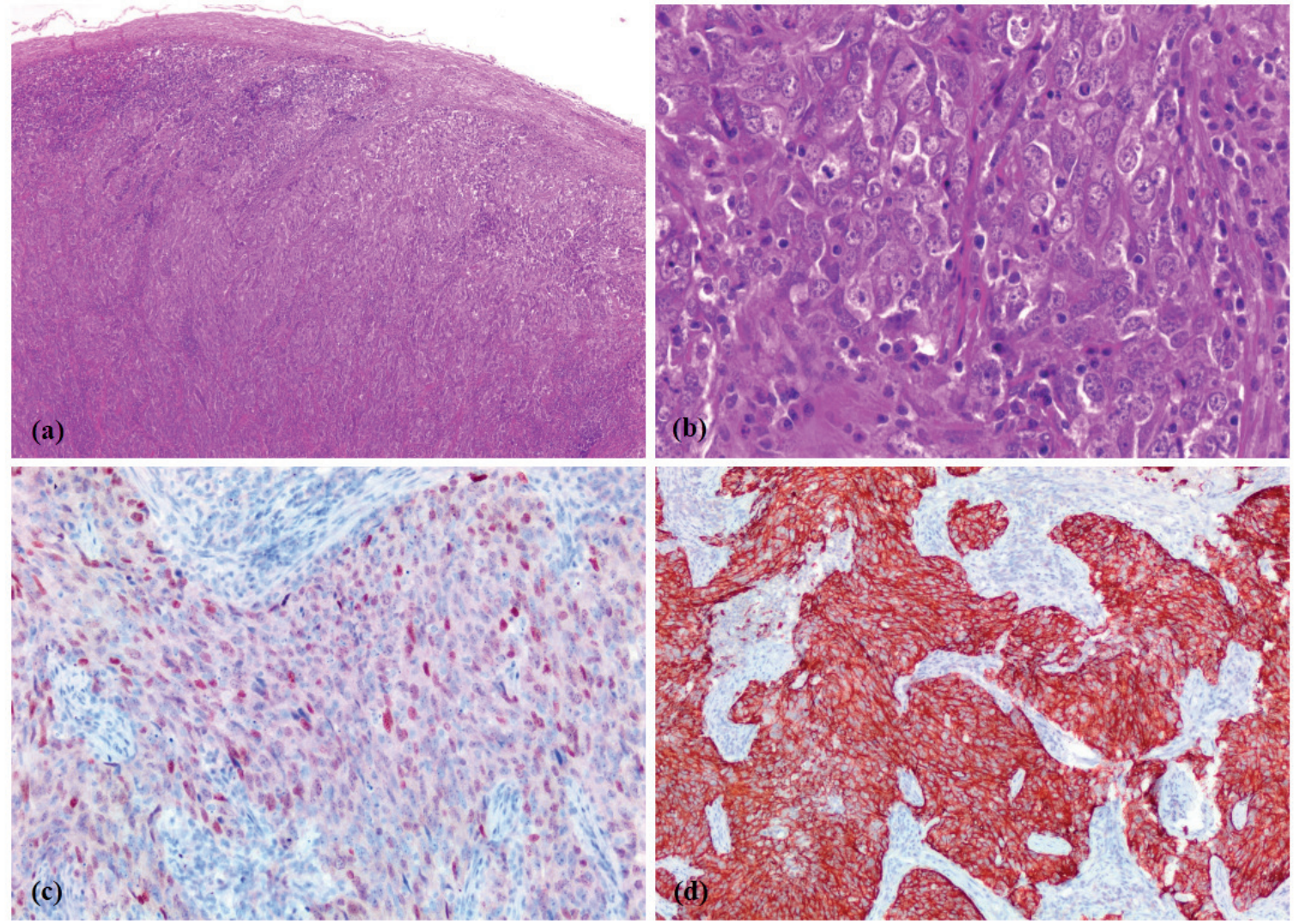

Fig. 4. (a): HE shows the tumor infiltrating the lymph node, (HEx50), (b): High power view of the tumor: A tumoral lesion composed of pleomorphic cells with eosinophilic cytoplasm, large vesicular nuclei and prominent nucleoli in syncytial pattern. Numerous mitosis is noted. (HEx400), (c): Nuclear positivity in tumor cells with immunohistochemical p63, (p63x200), and (d): Strong cytoplasmic staining in tumor cells with immunohistochemical HMW-CK, (HMW-CKx100).

\section{Discussion}

Kartagener's syndrome, also called immotile cilia syndrome, is a rare clinical entity inherited as an autosomal recessive trait. It is characterized by the triad of the sinusitis, bronchiectasis and situs inversus. It is a genetically heterogeneous disease with primary ciliary dyskinesia. Many genes may be affected. However, the main problem is the dysfunction of the cilia and impaired mucociliary clearance. ${ }^{1-3}$ Clinical findings are usually respiratory findings including unexplained respiratory distress in term neonate, daily productive cough since early infancy, daily nonseasonal rhinosinusitis since early infancy, chronic otitis media and persistent middle ear effusions, digital clubbing (rare in children), atypical asthma unresponsive to therapy, recurrent pneumonias and bronchiectasis, left-right laterality defects, situs inversus totalis or heterotaxy with or without complex congenital heart disease, and miscellaneous findings such as male infertility (immotile sperm), female subinfertility, ectopic pregnancy and hydrocephalus. ${ }^{1-3}$ The analysis of ciliate epithelial cells in order to assess function and ultrastructure may aid diagnosis. There is no single gold standard test and diagnosis should be made in a specialized center following review of clinical history. The genetic analysis is complicated by multiple existing phenotypes. Although, genetic testing was not recommended as part of initial diagnostic testing. Unfortunately, biopsy analysis and genetic test could not be done in this case. ${ }^{21}$ 
A few cases of malignant diseases have been reported in primary ciliar dyskinesia or KS. These reported cancers to date are renal cell carcinoma, testicular germ cell tumor, lung cancer, carcinoma of the ethmoid labyrinth, colon carcinoma, angioimmunoblastic $\mathrm{T}$ cell lymphoma, adenosquamous carcinoma of the paranasal sinuses, adenocarcinoma of the cervix uteri and endometrium, adrenal adenocarcinoma and papillary thyroid carcinoma. $^{4-18}$ It is seen that most of these tumors are tissue or organ cancers with ciliated epithelium and all of the cancers have occurred in adulthood or elderly, except one pediatric patient. The majority of these tumors can be explained by impaired mucociliary clearance and exposure to chronic irritations.

Angioimmunoblastic $\mathrm{T}$ cell lymphoma, is a rare tumor, particularly diagnosed in pediatric patients. The case was reported 6 years after a heart transplant in a pediatric patient with primary ciliary dyskinesia. Immunosuppressive drugs used after the heart transplant are usual suspected agents but it is not possible to completely rule out the role of primary ciliary dyskinesia. ${ }^{14}$ Another interesting case is adenosquamous carcinoma of paranasal sinuses. It is mostly seen in the $5^{\text {th }}$ and $6^{\text {th }}$ decades of the life. However, the presentation of this tumor at the age of 34 years in this patient with KS suggests that it may be associated with disruption of mucociliary clearance. ${ }^{15}$

Nasopharyngeal carcinoma is a rare tumor of childhood which originates from the epithelium of the nasopharynx. The association of EpsteinBarr virus with undifferentiated nasopharyngeal carcinoma is well known in children. ${ }^{19,20}$ Herein, we present a case of nasopharyngeal carcinoma in a child with KS. To our knowledge, this is the first report of nasopharyngeal carcinoma in a child with KS. In our patient, the presence of carcinoma originating from nasopharynx with ciliated epithelium suggests the contribution of dysfunction of the cilia and impaired mucociliary clearance to the carcinogenesis. In our patient, the most important limitation for the diagnosis of KS was the lack of ciliary ultrastructure on electron micrographs or genetic examination.

In conclusion, malignant diseases of tissue or organs with ciliated epithelium should be kept in mind in the follow-up of patients with KS or primary ciliary dyskinesia.

\section{REFERENCES}

1. Tadesse A, Alemu H, Silamsaw M, Gebrewold Y. Kartagener's syndrome: a case report. J Med Case Rep 2018; 12: 5.

2. Dalar L. Kartagener syndrome, primary ciliary dyskinesia. Turkiye Klinikleri J Pulm Med-Special Topics 2016; 9: 59-64.

3. Mishra M, Kumar N, Jaiswal A, Verma AK, Kant S. Kartagener's syndrome: a case series. Lung India 2012; 29: 366-369.

4. Jiménez Verdejo A, Martínez Torres JL, Palao Yago $\mathrm{F}$, et al. Renal cell carcinoma in patient with situs inversus and Kartagener syndrome. Actas Urol Esp 2000; 24: 169-172.

5. Bertini JE Jr, Boileau MA. Renal cell carcinoma in a patient with situs inversus totalis. J Surg Oncol 1987; 34: 29-31.

6. Saglam E, Turk A, Selimoglu A, Demirkol MK, Poci Saglam N, Ozgul A. Renal cell carcinoma in a patient with Kartagener syndrome: first case report in English language. J Urol Surg 2015; 1: 33-35.

7. Oake J, Drachenberg D. A case of renal cell carcinoma in a patient with situs inversus: operative considerations and a review of the literature. Can Urol Assoc J 2017; 11: E233-E236.

8. Meyer $\mathrm{CH}$. On the combination of Kartagener syndrome and malignant embryonal testis teratoma. Frankf Z Pathol 1966; 76: 21-31.

9. Ramos Barselo E, Portillo Martín JA, Correas Gómez MA, et al. Testicular seminoma in a patient with Kartagener's syndrome. Arch Esp Urol 2008; 61: 431434.

10. Horie M, Arai H, Noguchi S, Suzuki M, Sakamoto Y, Oka T. Kartagener syndrome with lung cancer and mediastinal tumor. Nihon Kokyuki Gakkai Zasshi 2010; 48: 375-378.

11. Inoue Y, Suga A, Sekido Y, Yamada S, Iwazaki M. A case of surgically resected lung cancer in a patient with Kartagener's syndrome. Tokai J Exp Clin Med 2011; 36: 21-24. 
12. Strelka J, Kuniak B. Carcinoma of the ethmoid labyrinth in Kartagener's syndrome. Cesk Otolaryngol 1972; 21: 78-80.

13. Yoshida J, Tsuneyoshi M, Nakamura K, Murakami T, Akamine Y. Primary ciliary dyskinesia with transverse colon carcinoma. Am J Clin Pathol 1986; 85: 101-104.

14. Kraus TS, Twist CJ, Tan BT. Angioimmunoblastic $\mathrm{T}$ cell lymphoma: an unusual presentation of posttransplant lymphoproliferative disorder in a pediatric patient. Acta Haematol 2014; 131: 95-101.

15. Naqvi SU, Hussain SI, Quadri S. Adenosquamous carcinoma of paranasal sinuses and Kartagener syndrome: an unusual combination. J Coll Physicians Surg Pak 2014; 24 (Suppl 1): S52-S54.

16. Zhang Y, Chen Y, Huang Z, Zhou F. Adenocarcinoma of the cervix uteri and endometrium combined with the Kartagener syndrome on FDG PET/CT. Clin Nucl Med 2015; 40: 922-923.
17. Hu W, Cheng L, Cheng B, et al. Adrenal adenocarcinoma with Kartagener's syndrome: a case report. Oncol Lett 2015; 10: 3635-3638.

18. Ren J, Wang X, He Z. Kartagener syndrome and papillary thyroid carcinoma: an unusual combination. Lin Chung Er Bi Yan Hou Tou Jing Wai Ke Za Zhi 2015; 29: 1911-1914.

19. Varan A, Ozyar E, Corapcioğlu F, et al. Pediatric and young adult nasopharyngeal carcinoma patients treated with preradiation cisplatin and docetaxel chemotherapy. Int J Radiat Oncol Biol Phys 2009; 73: 1116-1120.

20. Kupeli S, Varan A, Ozyar E, et al. Treatment results of 84 patients with nasopharyngeal carcinoma in childhood. Pediatr Blood Cancer 2006; 46: 454-458.

21. Barbato A, Frischer T, Kuehni CE, et al. Primary ciliary dyskinesia: a consensus statement on diagnostic and treatment approaches in children. Eur Respir J 2009; 34: 1264-1276. 